Article

\title{
Evaluation of the Antioxidant Activity of Syzygium cumini Leaves
}

\section{Zhi Ping Ruan ${ }^{1,2}$, Liang Liang Zhang ${ }^{1,2}$ and Yi Ming Lin ${ }^{1,2, *}$}

1 Key Lab of Ministry of Education for Coast and Wetland Ecosystems, Xiamen 361005; P.R. China; E-mails: rzp20012001@yahoo.com.cn (Z-P. R.); zh1120086@gmail.com (L-L.Z.)

2 Department of Biology, School of Life Sciences, Xiamen University, Xiamen 361005; P.R. China

* Author to whom correspondence should be addressed; E-mail: linym@xmu.edu.cn; Tel.: (+86) 5922187657.

Received: 22 August 2008; in revised form: 10 October 2008 / Accepted: 13 October 2008 / Published: 16 October 2008

\begin{abstract}
The antioxidant activity of Syzygium cumini leaf extracts was investigated using the 2,2-diphenyl-1-picrylhydrazyl (DPPH) free radical-scavenging and ferric-reducing antioxidant power (FRAP) assays. The methanolic extract and its four water, ethyl acetate, chloroform, and $n$-hexane fractions were prepared and subjected to antioxidant evaluation. The results showed that the ethyl acetate fraction had stronger antioxidant activity than the other ones. HPLC data indicated that $S$. cumini leaf extracts contained phenolic compounds, such as ferulic acid and catechin, responsible for their antioxidant activity. A significant linear relationship between antioxidant potency, free radical-scavenging ability and the content of phenolic compounds of leaf extracts supported this observation.
\end{abstract}

Keywords: Syzygium cumini; Antioxidant activity; Free radicals; High performance liquid chromatography

\section{Introduction}

Consumption of fruits and vegetables is shown to lower the risk for chronic diseases such as cancer, cardiovascular diseases and stroke [1]. The positive health effects may be due to high contents of 
certain phenolic compounds in plant-derived foods [2]. Recently, phytochemicals and their effects on human health have been intensively studied. In particular, a search for antioxidants, hypoglycemic agents, and anticancer agents in vegetables, fruits, teas, spices and medicinal herbs has attracted great attention.

S. cumini (L.) Skeels has been attributed in the Indian folklore medicine system to possess several medicinal properties [3]. The bark of the plant is astringent, sweet, refrigerant, carminative, diuretic, digestive, antihelminthic, febrifuge, constipating, stomachic and antibacterial. The fruits and seeds are used to treat diabetes, pharyngitis, spleenopathy, urethrorrhea and ringworm infection. The leaves have been extensively used to treat diabetes, constipation [4], leucorrhoea, stomachalgia, fever, gastropathy, strangury and dermopathy [3], and to inhibit blood discharges in the faeces [4]. The plant possesses acetyl oleanolic acid, triterpenoids, ellagic acid, isoquercitin, quercetin, kaempferol and myricetin in different concentrations [5]. Most of these compounds have been reported to possess antioxidant and free radical scavenging activities [6]. The chemical composition and antioxidant activity of S. cumini fruits have been studied recently [7,8], but there is scant information about the antioxidant activity of S. cumini leaves. In this study, the total phenolic content of $S$. cumini leaves was determined, and their antioxidant properties were also evaluated.

\section{Results and Discussion}

\section{Preparation of the methanolic extract and its fractions}

Due to the complicated constituents and pharmacological diversities of plants, in vitro bioassayguided fractionation has been effectively applied to screen the biological activities that contribute important indications for investigating the characteristics of active components [9]. The methanolic $S$. cumini leaf extract (ME) was fractionated by solvent-solvent partitioning to obtain four water (WtF), ethyl acetate $(\mathrm{EaF})$, chloroform $(\mathrm{CfF})$, and $n$-hexane $(\mathrm{HxF})$ fractions. The recoveries of $\mathrm{WtF}, \mathrm{EaF}, \mathrm{CfF}$, and $\mathrm{HxF}$ were about $37.33 \%, 5.33 \%, 4.01 \%$, and $24.67 \%$, indicating that the $S$. cumini leaf constituents belong mainly to the two opposing extremes of polarity.

\section{Total phenolic and total flavonoid content}

Phenols are very important plant constituents because of their radical scavenging ability due to their hydroxyl groups [10]. The phenolics content may contribute directly to the antioxidative action [11]. It has been suggested that polyphenolic compounds have inhibitory effects on mutagenesis and carcinogenesis in humans [6]. Consequently, the antioxidant activities of plant/herb extracts are often explained by their total phenolics and flavonoid contents with good correlation. The total phenolic content in the methanolic extract of $S$. cumini was $610.32 \pm 9.03 \mathrm{mg} / \mathrm{g}$ while the flavonoid content was $451.50 \pm 9.85 \mathrm{mg} / \mathrm{g}$. These results demonstrate that flavonoids represent the main group of phenolic compounds in S. cumini leaves. 


\section{DPPH free radical-scavenging assay}

The DPPH free radical is a stable free radical, which has been widely accepted as a tool for estimating free radical-scavenging activities of antioxidants [12]. The percentages of remaining DPPH in the presence of the ME and its fractions at different concentrations are shown in Table 1.

Table 1. Remaining DPPH and ferric reducing power after addition of the methanolic extract (ME) of S. cumini leaves and its fractions $(\mathrm{n}=3)$.

\begin{tabular}{cccccc}
\hline $\begin{array}{c}\text { Concentration } \\
(\boldsymbol{\mu} / \mathbf{m L})\end{array}$ & $\mathbf{M E}$ & $\mathbf{H x F}$ & $\mathbf{W t F}$ & $\mathbf{E a F}$ & $\mathbf{C f F}$ \\
\hline $\mathrm{DPPH}^{a}$ & & & & & \\
15.63 & $92.78 \pm 0.50 \mathrm{D}$ & $91.99 \pm 0.37 \mathrm{D}$ & $91.03 \pm 0.61 \mathrm{D}$ & $90.26 \pm 3.55 \mathrm{D}$ & $88.42 \pm 1.08 \mathrm{D}$ \\
31.25 & $86.92 \pm 0.78 \mathrm{C}$ & $90.10 \pm 0.18 \mathrm{C}$ & $86.02 \pm 1.82 \mathrm{C}$ & $81.73 \pm 0.43 \mathrm{C}$ & $83.57 \pm 0.98 \mathrm{C}$ \\
62.5 & $74.25 \pm 0.45 \mathrm{~B}$ & $86.78 \pm 0.84 \mathrm{~B}$ & $75.72 \pm 1.67 \mathrm{~B}$ & $69.15 \pm 0.30 \mathrm{~B}$ & $73.52 \pm 0.39 \mathrm{~B}$ \\
125 & $49.27 \pm 3.35 \mathrm{~A}$ & $79.09 \pm 0.67 \mathrm{~A}$ & $56.85 \pm 2.66 \mathrm{~A}$ & $45.95 \pm 0.72 \mathrm{~A}$ & $56.93 \pm 1.02 \mathrm{~A}$ \\
& & & & \\
FRAP & & & & & \\
15.63 & $0.13 \pm 0.01 \mathrm{a}$ & $0.06 \pm 0.01 \mathrm{a}$ & $0.10 \pm 0.00 \mathrm{a}$ & $0.11 \pm 0.01 \mathrm{a}$ & $0.11 \pm 0.01 \mathrm{a}$ \\
31.25 & $0.19 \pm 0.01 \mathrm{~b}$ & $0.07 \pm 0.00 \mathrm{a}$ & $0.16 \pm 0.01 \mathrm{~b}$ & $0.20 \pm 0.00 \mathrm{~b}$ & $0.18 \pm 0.00 \mathrm{~b}$ \\
62.5 & $0.33 \pm 0.02 \mathrm{c}$ & $0.10 \pm 0.00 \mathrm{~b}$ & $0.27 \pm 0.01 \mathrm{c}$ & $0.35 \pm 0.01 \mathrm{c}$ & $0.31 \pm 0.01 \mathrm{c}$ \\
125 & $0.60 \pm 0.01 \mathrm{~d}$ & $0.15 \pm 0.00 \mathrm{c}$ & $0.51 \pm 0.00 \mathrm{~d}$ & $0.68 \pm 0.01 \mathrm{~d}$ & $0.55 \pm 0.01 \mathrm{~d}$ \\
\hline
\end{tabular}

${ }^{a}$ Data are presented as the percentage of remaining DPPH; ${ }^{b}$ Data are presented as the absorbance at $593 \mathrm{~nm}$; Different letters on the same column show significant differences from each other at $P<$ 0.05; Statistical analysis was done by Duncan's multiple range tests.

The proportions of the remaining DPPH decreased slightly with the $\mathrm{WtF}$ and $\mathrm{CfF}$. Great decreases in a concentration-dependent manner of the remaining DPPH in ME and EaF indicated that with the exception of HxF, S. cumini extracts possess potent free radical-scavenging activity. By comparing the $\mathrm{IC}_{50}$ value of the $\mathrm{ME}$ and those of its active fractions with that of the authentic antioxidants, BHA and Vit. C (Table 2), it was found that the antioxidant activity of $\mathrm{EaF}\left(\mathrm{IC}_{50}: 112.79 \mu \mathrm{g} / \mathrm{mL}\right)$ was lower than that of Vit. C $\left(\mathrm{IC}_{50}: 71.30 \mu \mathrm{g} / \mathrm{mL}\right)$, but not significantly different from that of BHA ( $\mathrm{IC}_{50}: 114.69$ $\mu \mathrm{g} / \mathrm{mL}$ ) and $\mathrm{ME}\left(\mathrm{IC}_{50}: 125.39 \mu \mathrm{g} / \mathrm{mL}\right)$. By comparing $\mathrm{ME}$ and its active fractions, the free radicalscavenging activities followed the order: $\mathrm{EaF} \approx \mathrm{ME}>\mathrm{CfF} \approx \mathrm{WtF}>\mathrm{HxF}$. The free radical-scavenging activity of the $\mathrm{CfF}, \mathrm{WtF}$ and $\mathrm{HxF}$ were lower than that of $\mathrm{EaF}$, which resulted from increasing the active components/units through condensation during the solvent-solvent partitioning processes. The results also indicated that the active components existed mainly in the medium-polarity EaF fraction. S. cumini contains quercetin and myricetin [8]. Flavonoids are well-known antioxidant constituents in plants [12]. Spartium junceum, a Turkish folk medicine, contains flavonoid glycosides, which possess potent antioxidant activity according to activity-guided fractionation [13]. Accordingly, the antioxidant activity of leaves of $S$. cumini may be related to its flavonoid constituents. A previous study has 
demonstrated that the leaf extract of $S$. cumini can protect against the radiation-induced DNA damage [14].

\section{Ferric reducing antioxidant power (FRAP)}

The FRAP assay is based on the ability of antioxidants to reduce $\mathrm{Fe}^{3+}$ to $\mathrm{Fe}^{2+}$ in the presence of TPTZ, forming an intense blue $\mathrm{Fe}^{2+}$-TPTZ complex with an absorption maximum at $593 \mathrm{~nm}$. The absorbance decrease is proportional to the antioxidant content [15]. All fractions showed high ferric reducing power with increasing concentration, with the exception of $\mathrm{HxF}$ (Table 1). At $125 \mu \mathrm{g} / \mathrm{mL}$, the reducing power of the $\operatorname{EaF}\left(\mathrm{A}_{593}=0.68\right)$ was superior to that of $\mathrm{ME}\left(\mathrm{A}_{593}=0.60\right), \mathrm{CfF}\left(\mathrm{A}_{593}=0.55\right)$ and $\mathrm{WtF}\left(\mathrm{A}_{593}=0.51\right)$. The FRAP value, expressed in ascorbic acid equivalents, was used to determine the antioxidant ability of the different extracts in present study. The FRAP values for the $S$. cumini leaf extracts were high, ranging from $2.32 \pm 0.02$ to $3.12 \pm 0.07 \mathrm{mmol} \mathrm{AAE} / \mathrm{g}$ (Table 2). In brief, the reducing power of ME and its active fractions exhibited the descending order of: EaF, ME, $\mathrm{CfF}$ and $\mathrm{WtF}$.

Table 2. Antioxidant activities of the methanolic extract (ME) of leaves of S. cumini and its fractions using the (DPPH) free radical-scavenging assay and the (FRAP) ferricreducing antioxidant power assay $(\mathrm{n}=3)$.

\begin{tabular}{ccc}
\hline \multirow{2}{*}{ Samples } & \multicolumn{2}{c}{ Antioxidant activity } \\
\cline { 2 - 3 } & $\mathbf{I C}_{\mathbf{5 0 / \mathbf { D P P H }}(\boldsymbol{\mu g} / \mathbf{m L})^{a}}$ & $\mathbf{F R A P}^{a}(\mathbf{m m o l} \mathbf{A A E} / \mathbf{g})^{b}$ \\
\hline $\mathrm{ME}$ & $125.39 \pm 7.55 \mathrm{~b}$ & $2.73 \pm 0.06 \mathrm{~d}$ \\
$\mathrm{HxF}$ & $479.56 \pm 9.31 \mathrm{~d}$ & $0.53 \pm 0.05 \mathrm{a}$ \\
$\mathrm{CfF}$ & $149.33 \pm 4.43 \mathrm{c}$ & $2.51 \pm 0.05 \mathrm{c}$ \\
$\mathrm{EaF}$ & $112.79 \pm 2.51 \mathrm{~b}$ & $3.12 \pm 0.07 \mathrm{e}$ \\
$\mathrm{WtF}$ & $150.66 \pm 6.95 \mathrm{c}$ & $2.32 \pm 0.02 \mathrm{~b}$ \\
$\mathrm{VitC}$ & $71.30 \pm 1.66 \mathrm{a}$ & -- \\
$\mathrm{BHA}$ & $114.69 \pm 1.95 \mathrm{~b}$ & $4.66 \pm 0.10 \mathrm{f}$ \\
\hline
\end{tabular}

${ }^{a}$ The antioxidant activity was evaluated as the concentration of the test sample required to decrease the absorbance at $517 \mathrm{~nm}$ by $50 \%$ in comparison to the control; ${ }^{b}$ FRAP values are expressed in mmol ascorbic acid equivalent/g sample in dry weight; Different letters on the same column show significant differences from each other at $P<0.05$; Statistical analysis was done by Duncan's multiple range tests.

In addition, in a comparison of the ferric reducing power of the $\mathrm{ME}$ and its active fractions with BHA, the reducing power of all extracts were lower than that of BHA (4.66 mmol AAE/g). This could be explained that antioxidants are reducing agents. Antioxidants are compounds capable of donating a single electron or hydrogen atom for reduction. However, not all reducing agents are antioxidants. The good correlation was observed between the DPPH and FRAP assay, with the regression equation was $y$ $=0.0096 x-0.1274(R=0.9905)$. The FRAP assay was found to be more sensitive than the DPPH free radical-scavenging assay, which is in agreement with the observation of Zheng and Wang [16]. 


\section{Correlations between total phenolic content and antioxidative function}

The free radical scavenging activity and reducing power of the methanolic extract were significantly related to their total phenolic content $\left(R_{\mathrm{DPPH}}=0.9930, R_{\mathrm{FRAP}}=0.9998\right)$ (Figure 1$)$. The methanolic extract exhibited the highest radical scavenging activity and ferric reducing power with the greatest amount of phenolic content. The presence of polyphenolic compounds in methanolic extract of $S$. cumini might be responsible for this high antioxidant activity.

Figure 1. Relationships between the total phenolic content and the ferric reducing power (a); the total phenolic content and the free radical scavenging activity (b) of the methanolic extract (ME) of S. cumini.
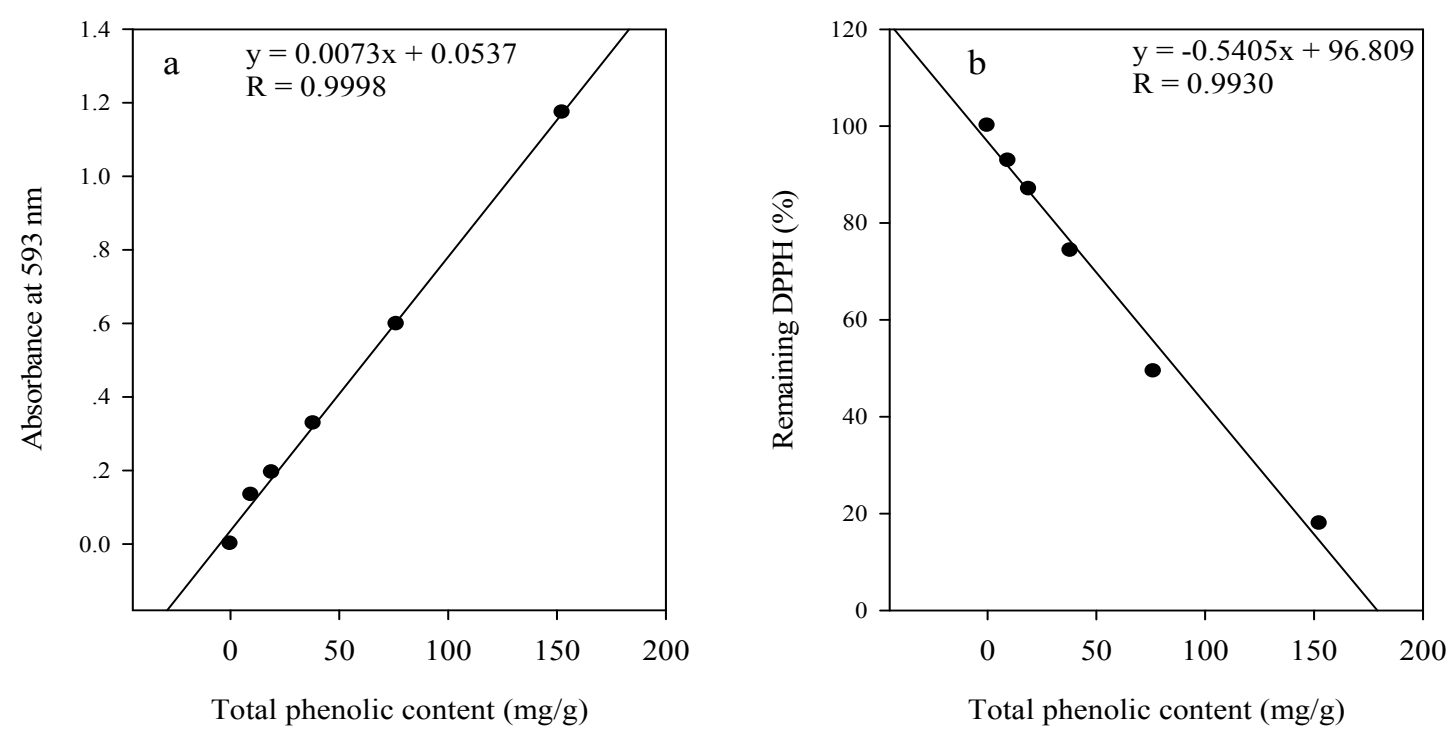

The extent of its antioxidant capacities were correlated with the contents of total phenolics and flavonoids. A linear regression analysis of the antioxidant activity with phenolic composition confirmed this observation. Benherlal and Arumughan [8] also observed that the seed ethanol extract of $S$. cumini had the extremely high antioxidant activity ( $\mathrm{IC}_{50 / \mathrm{DPPH}}$ of $8.6 \pm 3.0 \mu \mathrm{g} / \mathrm{mL}$ ).

Figure 2. Relationships between the total phenolic content and the ferric reducing power (a); the total phenolic content and the free radical scavenging activity (b) of the five extracts of S. cumini.
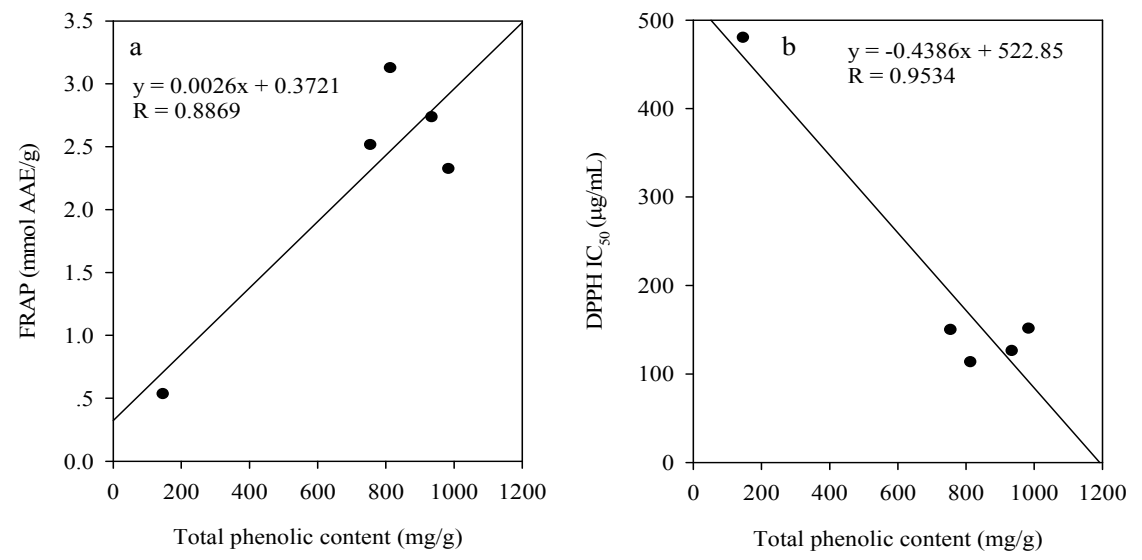
In addition, the correlations between the total phenolic content of the five extracts and the free radical scavenging activity and reducing power were shown in Figure 2. The significant relationships between total phenolic contents of five extracts and the antioxidative activities suggest that phenolics might be the major antioxidant compounds in studied extracts.

\section{Determination of phenolic compounds}

Phenolic compounds, such as quercetin, rutin, narigin, catechins, caffeic acid, gallic acid and chlorogenic acid, are very important plant constituents because of their antioxidant activities [17]. RPHPLC coupled with UV-Vis DAD was employed to separate, identify and quantify phenolic compounds in the methanolic extract of $S$. cumini leaves and its fractions. The concentrations were determined by calculating the HPLC peak areas which are proportional to the amount of analytes in a peak and presented as the mean of three determinations which were highly repeatable. Figure 3a shows the chromatogram of authentic standards of catechin and ferulic acid. These phenolic compounds have been identified in the methanolic extract of S. cumini and its fractions according to their retention times and spectral characteristics of their peaks against those of standards (Figure 3b, c, d), as well as by spiking the samples with standards.

Figure 3. HPLC chromatogram (280 nm) of (a) authentic standards (1) catechin and (2) ferulic acid and (b) methanolic extract (c) $n$-hexane fraction (d) chloroform fraction (e) ethyl acetate fraction (f) water fraction of $S$. cumini leaves.
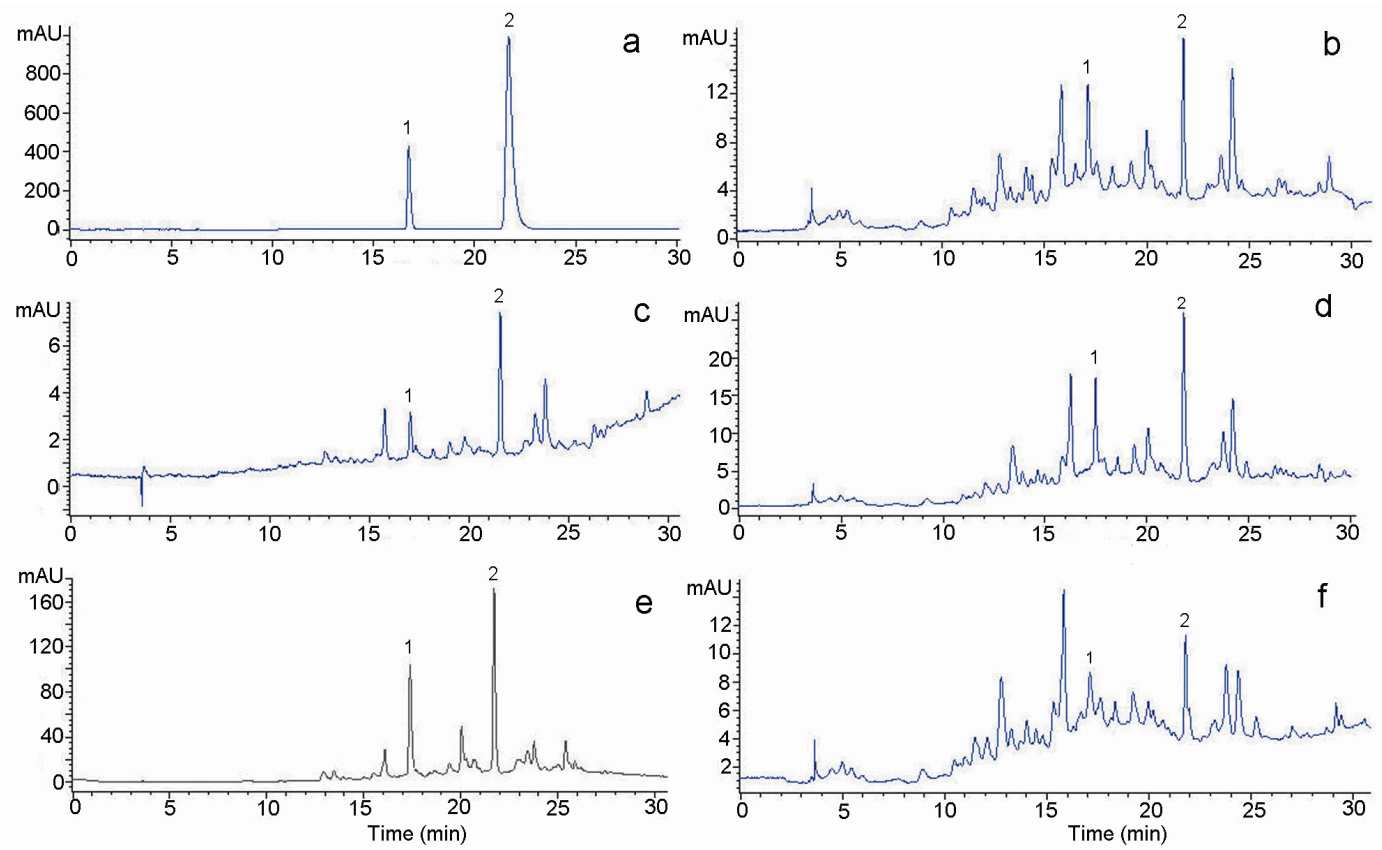

The result from the chromatograms indicated that EaF contained the highest content of catechin and ferulic acid. As shown in Figure 4, EaF contained approximately 7-fold more catechin and about 9-fold more ferulic acid than ME. By comparing the different fractions, the content of catechin and ferulic acid decreased in the same order of $\mathrm{EaF}>\mathrm{CfF}>\mathrm{WtF} \approx \mathrm{ME}>\mathrm{HxF}$, and the rank order of $\mathrm{ME}$ and $\mathrm{CfF}$ was different according to their antioxidant potency and free radical-scavenging ability. This 
result indicates that, besides phenolic acids, the other complex phenolic compounds in $S$. cumini extracts may also be responsible for the antioxidant activity. The ethyl acetate solution is more suitable for the extraction of both catechin and ferulic acid. The higher yield of these compounds might contribute to the higher antioxidant activity of ethyl acetate fraction when compared with other fractions [18].

Figure 4. Concentrations of catechin and ferulic acid recovered from the methanolic extract (ME) of $S$. cumini leaves and its fractions. For catechin, different small letters show significant differences from each other at $P<0.05$; for ferulic acid, different capital letters show significant differences from each other at $P<0.05$.

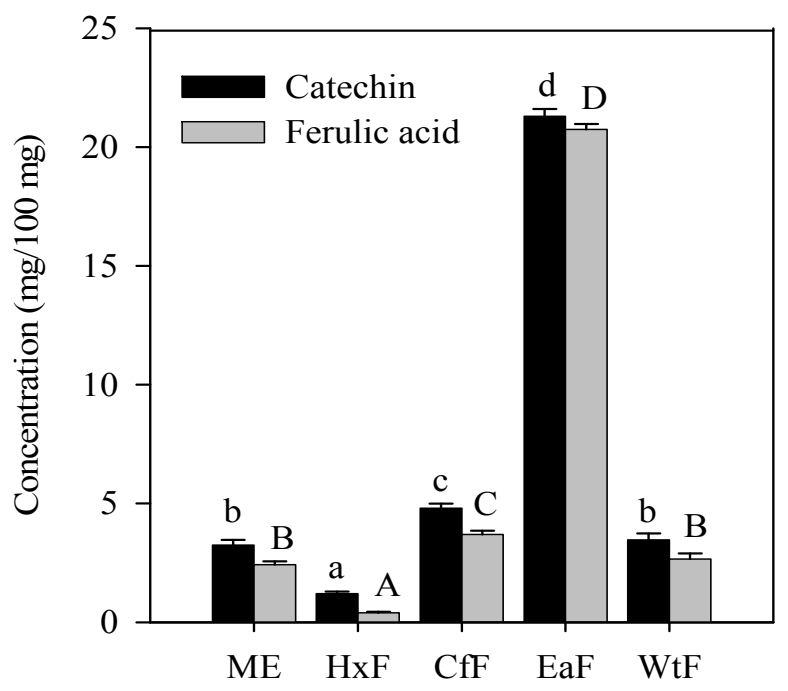

Catechin, a monomeric flavanol, is reported to have hydroxyl [19], peroxyl [20], superoxide [21] and DPPH [22] radical scavenging activities. Moreover, it can chelate iron [23]. Nakao et al. [24] found that ECG, epicatechin and catechin had a peroxyl radical scavenging activity ten times higher than L-ascorbate and $\beta$-carotene when tested on bacteria. Nanjo et al. [25] reported that DPPH radical scavenging activity of catechin and epicatechin was lower than EGC, ECG, and EGCG. Recently, catechins have been used as natural antioxidant in oils and fats against lipid oxidation, supplement for animal feeds both to improve animal health and to protect animal products, an antimicrobial agent in foodstuffs and a health functional ingredient in various foods and dietary supplements [26]. It was hypothesized that catechins might be localized near the membrane surface scavenging aqueous phase radicals [27] and preventing the consumption of $\alpha$-tocopherol, whereas the latter mainly acts as a scavenger of lipid peroxyl radicals within the low-density lipoproteins. The study of the catechins is particularly important for the understanding of the antioxidant properties of teas, in which flavanols such as catechins and catechin/gallate esters constitute $26.7 \%$ of the solid content of freeze-dried green tea [28]. Ferulic acid and its precursors, $p$-coumaric acid and caffeic acid are synthesized in plants. Ferulic acid occurs in cereals and vegetables, such as rice, wheat, oats, tomatoes, asparagus, olives and many other plants. Recently, many studies have focused on the antioxidant potentialities of ferulic acid and its $n$-alkyl esters [29]. Sanchez-Moreno et al. [30] indicated that the inhibition of lipid oxidation of the phenolic compounds and antioxidant standards followed the order: rutin, ferulic acid $>$ tannic acid, gallic acid, resveratrol $>$ BHA, quercetin $>$ tocopherol $>$ caffeic acid, in a linoleic acid system. 
Meanwhile, the free radical-scavenging activity was in the order: gallic acid $>$ tannic acid, caffeic acid, quercetin, BHA, rutin $>$ ferulic acid, tocopherol, resveratrol. However, some studies indicated that ferulic acid was ineffective, and even promoted the oxidation of low density lipoprotein induced by copper [31]. According to our observation, catechin and ferulic acid may have important roles in the antioxidant activity and free radical scavenging ability of $S$. cumini leaf extracts.

\section{Conclusions}

Total phenolic content in methanolic extract of $S$. cumini leaves was $610.32 \pm 9.03 \mathrm{mg} / \mathrm{g}$ while the flavonoid content of the methanolic extract was $451.50 \pm 9.85 \mathrm{mg} / \mathrm{g}$. The five extracts of $S$. cumini leaves have potent antioxidant activity according to the DPPH and FRAP assays. The HPLC data indicated that S. cumini leaf extracts contained phenolic compounds, such as ferulic acid and catechin. The antioxidant activity of $S$. cumini leaf extracts may be related to their phenolic substrates. A significant linear relationship between antioxidant potency, free radical-scavenging ability and the content of phenolic compounds of leaf extracts supported this observation.

\section{Experimental}

\section{Chemicals and plant materials}

Vitamin C (Vit.C), butylated hydroxyanisole (BHA), tannic acid, ferulic acid, rutin, catechin, TPTZ (2,4,6-tripyridyl-S-triazine) and DPPH (2,2-diphenyl-1-picrylhydrazyl) were purchased from SigmaAldrich (St. Louis, MO). Milli-Q water and HPLC grade $\mathrm{CH}_{3} \mathrm{CN}$ for analytical RP-HPLC, and other chemicals were of analytical reagent (AR) purity grade. Mature leaves of S. cumini were collected at the campus of Xiamen University (Xiamen, P.R. China) and immediately freeze dried and ground.

\section{Extraction procedure}

Leaf samples $(120 \mathrm{~g})$ were extracted by macerating them in methanol for 7 days at room temperature in a dark cabinet. After solvent evaporation in a rotary evaporator, the methanolic extract (ME) was further fractionated through solvent-solvent partitioning to obtain different fractions. The four solvents used for solvent-solvent partitioning to cover the range from high to low polarity were water, ethyl acetate, chloroform, and $n$-hexane. The $\mathrm{ME}$ and its four water (WtF), ethyl acetate (EaF), chloroform $(\mathrm{CfF})$ and $n$-hexane $(\mathrm{HxF})$ fractions were stored in an electronic dry cabinet protected from light with aluminum foil after solvent evaporation.

\section{Determination of total phenolics and total flavonoid content}

Total phenolics was measured with the Prussian blue method [32], using tannic acid as the standard. Total flavonoid content was determined according to a known method [33] with a slight modifications, the methanolic extract $(2 \mathrm{mg})$ was added to $2 \mathrm{~mL}$ distilled water, followed by $\mathrm{NaNO}_{2}(0.3 \mathrm{~mL}, 5 \%)$. After $6 \mathrm{~min}$ at $25{ }^{\circ} \mathrm{C}, \mathrm{Al}\left(\mathrm{NO}_{3}\right)_{3}(0.3 \mathrm{~mL}, 10 \%)$ was added. The reaction mixture was treated with 
$\mathrm{NaOH}(4 \mathrm{~mL}, 1 \mathrm{M})$ after $6 \mathrm{~min}$, diluted to volume $(10 \mathrm{~mL})$ with $50 \%$ ethanol solution and, after a thorough mixing the absorbance at $500 \mathrm{~nm}$ was read. Rutin was used as the standard and the total flavonoid content was expressed as rutin equivalents (RE) $\mathrm{mg} / \mathrm{g}$ dry weight of the extracts.

Free radical scavenging ability on 2,2-diphenyl-1-picrylhydrazyl

To assess the scavenging ability on 2,2-diphenyl-1-picrylhydrazyl (DPPH), each extract (0.1 mL, $15-250 \mu \mathrm{g} / \mathrm{mL})$ in methanol was mixed with methanol solution $(3 \mathrm{~mL})$ containing DPPH radicals $(0.004 \%, \mathrm{w} / \mathrm{w})$. The mixture was shaken vigorously and left to stand for $30 \mathrm{~min}$ in the dark before measuring the absorbance at $517 \mathrm{~nm}$ against a blank [34]. Then the scavenging ability was calculated using the following equation: Scavenging ability $(\%)=\left[\left(\Delta \mathrm{A}_{517}\right.\right.$ of control $-\Delta \mathrm{A}_{517}$ of sample $) / \Delta \mathrm{A}_{517}$ of control] $\times 100$. Three replicates were carried out.

\section{Ferric reducing/antioxidant power (FRAP) assay}

The procedure was as described by Benzie and Strain [15]. Briefly, $3 \mathrm{~mL}$ of FRAP reagent, prepared freshly, was mixed with $0.1 \mathrm{~mL}$ of test sample, or methanol (for the reagent blank). The FRAP reagent contained $10 \mathrm{mM}$ TPTZ solution $(2.5 \mathrm{~mL})$ in $40 \mathrm{mM} \mathrm{HCl}$ plus $20 \mathrm{mM} \mathrm{FeCl}_{3}(2.5 \mathrm{~mL})$ and $0.3 \mathrm{M}$ acetate buffer $(\mathrm{pH} 3.6,25 \mathrm{~mL})$. The absorbance of reaction mixture was measured spectrophoto-metrically at $593 \mathrm{~nm}$ after incubation at $25{ }^{\circ} \mathrm{C}$ for $10 \mathrm{~min}$. FRAP assay records the change in absorbance at $593 \mathrm{~nm}$ owing to the formation of a blue colored $\mathrm{Fe}^{\mathrm{II}}$-tripyridyltriazine compound from colorless oxidized $\mathrm{Fe}^{\mathrm{III}}$ form by the action of electron donating antioxidants. All solutions were used on the day of preparation. The FRAP values, expressed in mmol ascorbic acid equivalents $(\mathrm{AAE}) / \mathrm{g}$ sample in dry weight were derived from a standard curve.

\section{HPLC analysis of phenolic compounds}

The contents of phenolic compounds in leaf extracts of $S$. cumini were determined by HPLC, performed with an Agilent 1100 diode array detector system equipped with a quaternary pump. The analyses were carried out on a Hypersil ODS column $(4.6 \mathrm{~mm} \times 250 \mathrm{~mm}, 2.5 \mu \mathrm{m})$ column. Extracts were filtered through a $0.45 \mu \mathrm{m}$ filter before use. Gradient B in A according to the elution profile $0-3$ $\min 2 \% \mathrm{~B}$ (isocratic), 3-20 min 2\%-25\% B (linear gradient), 20-25 min 25\%-35\% B (linear gradient), (A) water $(0.05 \% \mathrm{TFA})$, (B) $\mathrm{CH}_{3} \mathrm{CN}(0.05 \% \mathrm{TFA})$; flow rate $1 \mathrm{~mL} / \mathrm{min}$; volume injected $10 \mu \mathrm{L}$; temperature $22{ }^{\circ} \mathrm{C}$; detection $280 \mathrm{~nm}$.

\section{Statistical analysis}

All measurements were replicated three times and one-way analysis of variance (ANOVA) was used The Duncan's multiple range tests were used to test the significant differences. All statistical analyses were performed with SPSS 11.0. 


\section{Acknowledgements}

This study was supported by the National Natural Science Foundation of China (No.30671646), by Program for New Century Excellent Talents in University (NCET-07-0725) and by Program for Innovative Research Team in Science and Technology in Fujian Province University.

\section{References}

1. Yeum, K.J.; Aldini, G.; Chung, H.Y.; Krinsky, N.I.; Russell, R.M. The activities of antioxidant nutrients in human plasma depend on the localization of attacking radical species. J. Nutr. 2003, 133, 2688-2691.

2. You, Y.L.; Duan, X.W.; Wei, X.Y.; Su, X.G.; Zhao, M.M.; Sun, J.; Ruenroengklin, N.; Jiang, Y.M. Identification of major phenolic compounds of Chinese water chestnut and their antioxidant activity. Molecules. 2007, 12, 842-852.

3. Warrier, P.K.; Nambiar, V.P.K.; Ramankutty, C. Indian Medicinal Plants. Orient Longman Ltd.: Hyderabad, India, 1996; vol. 5, pp. 225-228.

4. Bhandary, M.J.; Chandrashekar, K.R.; Kaveriappa, K.M. Medical ethnobotany of the siddis of Uttara Kannada district, Karnataka, India. J. Ethnopharmacol. 1995, 47, 149-158.

5. Rastogi, R.M.; Mehrotra, B.N. Compendium of Indian Medicinal Plants. Central Drug Research Institute: Lucknow, India, 1990; vol. 1, pp. 388-389.

6. Tanaka, M.; Kuei, C.W.; Nagashima, Y.; Taguchi, T. Application of antioxidative maillard reaction products from histidine and glucose to sardine products. Nippon Sui. Gakk. 1998, 54, 1409-1414.

7. Banerjee, A.; Dasgupta, N.; De, B. In vitro study of antioxidant activity of Syzygium cumini fruit. Food Chem. 2005, 90, 727-733.

8. Benherlal, P.S.; Arumughan, C. Chemical composition and in vitro antioxidant studies on Syzygium cumini fruit. J. Sci. Food Agric. 2007, 87, 2560-2569.

9. Lacikova, L.; Muselik, J.; Masterova, I.; Grancai, D. Antioxidant activity and total phenols in different extracts of four Staphylea L. species. Molecules 2007, 12, 98-102.

10. Hatano, T.; Edamatsu, R.; Hiramatsu, M.; Mori, A.; Fujita,Y.; Yasuhara, T.; Yoshida, T.; Okuda, T. Effect of interaction of tannins with co-existing substances VI. Effect of tannins and related polyphenols on superoxide anion radical and on DPPH radical. Chem. Pharm. Bull. 1989, 37, 2016-2021.

11. Duh, P.D.; Tu, Y.Y.; Yen, G.C. Antioxidant activity of water extract of Harng Jyur (Chrysanthemum morifolium Ramat). Leb-ensm. Wiss. Technol. 1999, 32, 269-277.

12. Fenglin, H.; Ruili, L.; Bao, H.; Liang, M. Free radical scavenging activity of extracts prepared from fresh leaves of selected Chinese medicinal plants. Fitoterapia 2004, 75, 14-23.

13. Yesilada, E.; Tsuchiya, K.; Takaishi, Y.; Kawazoe, K. Isolation and characterization of free radical scavenging flavonoid glycosides from the flowers of Spartium junceum by activityguided fractionation. J. Ethnopharmacol. 2000, 73, 471-478. 
14. Jagetia, G.C.; Baliga, M.S. Syzygium cumini (Jamun) reduces the radiation-induced DNA damage in the cultured human peripheral blood lymphocytes: a preliminary study. Toxicol. Lett. 2002, 132, 19-25.

15. Benzie, I.F.F.; Strain, J.J. The ferric reducing ability of plasma (FRAP) as a measure of "antioxidant power": the FRAP assay. Anal. Biochem. 1996, 239, 70-76.

16. Zheng, W.; Wang, S.Y. Antioxidant activity and phenolic compounds in selected herbs. J. Agric. Food Chem. 2001, 49, 5165-5170.

17. Paganga, G.; Miller, N.; Rice-Evans, C.A. The polyphenolic content of fruit and vegetables and their antioxidant activities. What does a serving constitute? Free Radical. Res. 1999, 30, $153-$ 162.

18. Oszmianski, J.; Wojdylo, A.; Lamer-Zarawska, E.; Swiader, K. Antioxidant tannins from Rosaceae plant roots. Food Chem. 2007, 100, 579-583.

19. Moini, H.; Guo, Q.O.; Packer, L.; Xanthine oxidase and xanthine dehydrogenase inhibition by the procyanidin-rich French maritime pine bark extract, pycnogenol: a protein binding effect. Adv. Exp. Med. Biol. 2002, 505, 141-149.

20. Scott, B.C.; Butler, J.; Halliwell, B.; Aruoma, O.I. Evaluation of the antioxidant actions of ferulic acid and catechins. Free Radic. Res. Commun. 1993, 19, 241-253.

21. Bors, W.; Michel, C. Antioxidant capacity of flavanols and gallate esters: pulse radiolysis studies. Free Radic. Biol. Med. 1999, 27, 1413-1426.

22. Fukumoto, L.R.; Mazza, G. Assessing antioxidant and prooxidant activities of phenolic compounds. J. Agric. Food Chem. 2000, 48, 3597-3604.

23. Morel, I.; Lescoat, G.; Cogrel, P.; Sergent, O.; Pasdeloup, N.; Brissot, P.; Cillard, P.; Cillard, J. Antioxidant and iron chelating activities of the flavonoids catechin, quercetin and diosmetin on iron-loaded rat hepatocyte cultures. Biochem. Pharmacol. 1993, 45, 13-19.

24. Nakao, M.; Takio, S.; Ono, K. Alkyl peroxyl radical-scavenging activity of catechins. Phytochemistry 1998, 49, 2379-2382.

25. Nanjo, F.; Goto, K.; Seto, R.; Suzuki, M.; Sakai, M.; Hara, Y. Scavenging effects of tea catechins and their derivativeson 1,1-diphenyl-2-picrylhydrazyl radical. Free Radic. Biol. Med. 1996, 21, 895-902.

26. Yilmaz, Y. Novel uses of catechins in foods. Trends Food Sci. Technol. 2006, 17, 64-71.

27. Terao, J.; Piskuli, M.; Yao, Q. Protective effects of epicatechin, epicatechin gallate and quercetin on lipid peroxidation in phospholipid bilayers. Arch. Biochem. Biop. 1994, 308, 278-284.

28. Salah, N.; Miller, N.J.; Paganga, G.; Tijburg, L.; Bolwell, G.P.; Rice-Evans, C.A. Polyphenolic flavanols as scavengers of aqueous phase radicals and as chain-breaking antioxidants. Arch. Biochem. Biophys. 1995, 322, 339-346.

29. Kanski, J.; Aksenova, M.; Stoyanova, A.; Butterfield, D.A. Ferulic acid antioxidant protection against hydroxyl and peroxyl radical oxidation in synaptosomal and neuronal cell culture systems in vitro: structure-activity studies. J. Nutr. Biochem. 2002, 13, 273-281.

30. Sanchez-Moreno, C.; Larrauri, J.A.; Saura-Calixto, F. Free radical scavenging capacity and inhibition of lipid oxidation of wines, grape juices and related polyphenolic constituents. Food Res. Inter. 1999, 32, 407-412. 
31. Cirico, T.L.; Omaye, S.T. Additive or synergetic effects of phenolic compounds on human low density lipoprotein oxidation. Food Chem. Toxicol. 2006, 44, 510-516.

32. Graham, H.D. Stabilization of the Prussian blue color in the determination of polyphenols. $J$. Agric. Food Chem. 1992, 40, 801-805.

33. Jia, Z.; Tang, M.; Wu, J. The determination of flavonoid content in mulberry and their scavenging effects on superoxide radicals. Food Chem. 1999, 64, 555-599.

34. Braca, A.; Tommasi, N.D.; Bari, L.D.; Pizza, C.; Politi, M.; Morelli, I. Antioxidant principles from Bauhinia terapotensis. J. Nat. Prod. 2001, 64, 892-895.

Sample Availability: Samples are available from the authors.

(C) 2008 by the authors; licensee Molecular Diversity Preservation International, Basel, Switzerland. This article is an open-access article distributed under the terms and conditions of the Creative Commons Attribution license (http://creativecommons.org/licenses/by/3.0/). 